\title{
An Instrumentalist Unification of Zetetic and Epistemic Reasons
}

\author{
Asbjørn Steglich-Petersen \\ Penultimate draft. Final version forthcoming in Inquiry
}

\begin{abstract}
Inquiry is an aim-directed activity, and as such governed by instrumental normativity. If you have reason to figure out a question, you have reason to take means to figuring it out. Beliefs are governed by epistemic normativity. On a certain pervasive understanding, this means that you are permitted - maybe required - to believe what you have sufficient evidence for. The norms of inquiry and epistemic norms both govern us as agents in pursuit of knowledge and understanding, and, on the surface, they do so in harmony. Recently, however, Jane Friedman (2020) has pointed out that they are in tension with each other. In this paper, I aim to resolve this tension by showing that reasons for acts of inquiry - zetetic reasons - and epistemic reasons for belief can both be understood as flowing from the same general normative principle: the transmission principle for instrumental reasons. The resulting account is a version of epistemic instrumentalism that offers an attractive unity between zetetic and epistemic normativity.
\end{abstract}

\section{Introduction}

Inquiry is an aim-directed activity, and as such governed by instrumental normativity. If you have reason to figure out a question, you have reason to take means to figuring it out. Beliefs are governed by epistemic normativity. On a certain pervasive understanding, this means that you are permitted - maybe required - to believe what you have sufficient evidence for. The norms of inquiry and epistemic norms both govern us as agents in pursuit of knowledge and understanding, and, on the surface, they do so in harmony. Recently, however, Jane Friedman (2020) has pointed out that, on the currently most pervasive understanding of them, these norms are in tension with each other. In this paper, I aim to resolve this tension by showing that reasons for acts of inquiry - zetetic reasons - and epistemic reasons for belief can both be understood as flowing from the same general normative principle: the transmission principle for instrumental reasons. The resulting account is a version of epistemic instrumentalism that offers an attractive unity between zetetic and epistemic normativity.

Here is how I will proceed. In $\$ 2$, introduce the currently pervasive understanding of norms of inquiry and epistemic norms, and Friedman's observation that they are in tension with each other. In $\$ 3$, I discuss Friedman's construal of the instrumental norm governing inquiry, point out some difficulties with it, and rely on this to motivate an alternative instrumental norm of inquiry, which takes the instrumental transmission principle as its basis. In $₫ 4$, I show how this 
principle allows us to derive reasons not only for acts of inquiry, but also for belief, and argue that we should identify epistemic reasons for belief with the reasons transmitted from the aim of inquiry. In effect, the resulting account of epistemic reasons is a version of epistemic instrumentalism, which should be unsurprising, given that it is derived from an instrumental principle governing inquiry. In $\ 5$, I show how this account explains the correct verdict in Friedman's central example of tension between epistemic and zetetic norms, before concluding in $\$ 6$.

\section{The Tension}

When evaluating epistemic agents, we can distinguish between two broad aspects of an agent's epistemic capacity and performance that we might focus on. The one broad aspect has to do with how well the agent's beliefs are supported by her current and changing epistemic circumstances how rational or justified her beliefs are in light of her evidence and other epistemically relevant facts about her current situation, and how well the agent responds to changes in those epistemic circumstances by updating her beliefs. For example, in light of my current evidence (writing the in fall of 2020), it would not be rational for me to believe that there will be a widely available Covid19 vaccine by Christmas, although we can imagine developments that would make such a belief rational. The norms and reasons governing this aspect of our epistemic performance are usually simply identified as 'epistemic' norms and reasons.

The other broad aspect has to do with how well the agent performs in impacting or bettering her epistemic situation, and how well she manages her epistemic resources - what questions she chooses to focus her attention on, how she goes about answering those questions, what she does to improve her ability to answer them, and so on. For example, if I am planning an international trip for Christmas, I would do well to devote time and energy to figuring out if a vaccine is likely to be widely available by then, and some ways of figuring this out are clearly better than others. For example, I would do better to consult the predictions of the WHO, than to rely on discussion threads on social media. Rather than concerning the narrow relationship between our beliefs and our evidence, this aspect concerns a broader kind of activity: inquiry. The norms and reasons governing inquiry, we can call 'zetetic' norms and reasons, to adopt Jane Friedman's recent term of art. ${ }^{1}$

\footnotetext{
${ }^{1}$ As Friedman (2020: fn 1) explains, 'zetetic' derives from the Greek verb ' $\zeta \eta \tau \varepsilon \omega$ ', which translates to 'seek for' or 'inquire after'.
} 
Although the former aspect of our epistemic performance has traditionally been the main focus of epistemology, the latter aspect concerning inquiry is at least as prominent - arguably more prominent - in our everyday assessments of epistemic agents. Think of a truly admirable epistemic agent, such as the mid-twentieth century British chemist Rosalind Franklin, who played an integral role in discovering the molecular structure of DNA. ${ }^{2}$ While we of course admire her ability and cautious attitude in forming beliefs that were supported by her evidence - displaying an impressive understanding of what her experiments indicated, not jumping to conclusions, keeping an open mind when the evidence did not yet support belief, etc. - we admire her even more, I think, as a creative and astute inquirer: as someone who asked the right questions, saw what sort of experiments and calculations might yield the evidence needed to answer them, and then skilfully and patiently carried them out. Not only did her beliefs match her evidence - she acted brilliantly so as to get the evidence needed for answering the questions that she so deftly asked.

How are epistemic and zetetic norms and reasons related to each other? A natural answer is that they must be very closely related. When we seek to answer a question, and take steps of inquiry to reach an answer, what we are ultimately after is a true and rational belief on the matter - a rational belief in the proposition that constitutes the true answer to the question we are interested in. And when we respond to the evidence that our inquiry uncovers, such a belief is exactly what we aim to acquire: a belief that is true and rational in light of the evidence. So, surely, the norms and reasons governing these aspects of our epistemic performance must be very closely related indeed.

However, according to the current orthodoxy on the matter, although epistemic and zetetic norms and reasons govern closely related activities, they are nevertheless fundamentally different. As Thomas Kelly (2003: \$5) puts this view, 'theoretical rationality' is a 'hybrid virtue', involving responsiveness to two fundamentally different kinds of reasons: epistemic reasons that consist of evidence and speak in favour of believing propositions in virtue of making it likely that the propositions are true; and a kind of practical reasons arising from the aim one adopts in setting out to answer questions by engaging in inquiry. Of particular importance here are practical instrumental reasons to take means that enable one to answer the relevant questions, means such as looking in the right direction, doing the experiments, making the calculations, and so on.

On this hybrid picture, the two sets of reasons each do their separate work in harmonious interplay. Consider Kelly's example (2003: 634): I become interested in a question (what made that noise?), and realise that I must do certain things to be able to answer it (turn around and look in the direction of the noise). The reason I thereby gain and respond to is an instrumental reason to

\footnotetext{
${ }^{2}$ For a compelling account, see Maddox (2003).
} 
take means to the aim of answering the question. Once I have responded to that instrumental reason, however, and I have secured the evidence needed to answer the question (seeing a cat), it is a different kind of reason that enjoins me to believe the answer (that the cat made the noise), namely an epistemic reason consisting of the uncovered evidence. The two kinds of reasons thus each do their separate normative work at different stages in the epistemic process - the process that, when all goes well, takes the agent from initial curiosity about a question to believing the true answer.

As Kelly points out (2003: 637), thus lending further support to the separateness of the two sets of norms and reasons, we can imagine an agent who is proficient in responding to the one kind of reasons, but not to the other. For example, we can imagine an agent who is perfectly epistemically rational in believing all and only those propositions that are supported by her evidence, but is extremely bad at taking effective means to bring herself into a position where she is able to answer the questions she is or ought to be interested in. Such an agent would end up with a lot of epistemically rational beliefs, but not necessarily about the matters that it would be most important to have beliefs about. And, vice versa, we might imagine an agent who always takes effective means to be able to answer questions of interest by engaging in inquiry, but never manages to form the right beliefs in light of the evidence that her inquiries uncover. So, on the face of things, it seems reasonable to view rational belief and rational inquiry as governed by separate sets of norms and reasons. And indeed, that is how they tend to be studied in current epistemology, where the main focus is on what it is rational to believe in light of one's current evidence, regardless of the processes of inquiry that have led the agent to that evidence. ${ }^{3}$

Recently, however, Jane Friedman (2020) has drawn attention to a puzzling tension between epistemic and zetetic norms and reasons, at least as they are currently understood. The currently most popular proposals for the epistemic norms governing belief seem to conflict with the most natural understanding of the zetetic norms governing inquiry. In a nutshell, the issue is this. Current proposals for epistemic norms deem believing $p$ permissible (or required, depending on the specific proposal) for an agent whenever the agent has sufficient evidence for $p$. However, forming those beliefs takes cognitive effort, and thus might impair one's ability to complete other cognitive tasks, such as the tasks involved in carrying out an inquiry. So, if those other tasks are required at a particular time by the zetetic norms, we might find ourselves in a situation where the zetetic norms require something that is incompatible with something that the epistemic norms

\footnotetext{
${ }^{3}$ For exceptions to this tendency, see e.g. Friedman (forthcoming; 2020; see also her 2018 and 2019), Kelp (2021; forthcoming a), Hookway (2006; 2008), and Thorstad (forthcoming).
} 
permit. But of course, something cannot be permissible if it is incompatible with something else that is required.

Consider Friedman's central example (2020: 502). ${ }^{4}$ Suppose that you need to know how many windows the Chrysler Building in Manhattan has, and that the only way of figuring this out is by counting the windows yourself. Doing the count takes an hour of focused work. Your need for this knowledge is urgent. So, insofar as the zetetic norms require that you to take means to your aims of inquiry, you ought to focus on counting. ${ }^{5}$ However, while you are counting, you could form countless evidentially well-supported beliefs about other matters. These beliefs could be formed in response to new evidence that you gain while counting (say, from idly watching people pass by), or in response to evidence that you already have. But forming all these beliefs would take away attention from your urgent task of counting, to the point of making it impossible to complete within the required time. So, it seems that you should try to ignore any evidence that might distract you, and not form the distracting beliefs, even if they would be well supported by your evidence. But this means that there are beliefs, which would be permitted (or perhaps even required) by the standard epistemic norms, that you nevertheless ought not to form.

On the surface, this tension between epistemic and zetetic norms might appear as a benign instance of the more general and familiar tension between epistemic and practical norms. If the zetetic norms sometimes require me to focus on a task of inquiry, and so forbid me from devoting cognitive effort to forming other beliefs in response to my evidence, then something similar will be the case for any of the many things that I can be required to do from a more general practical perspective. For example, if I am practically required to run as fast as I can right now (say, to save a child from drowning), and cannot do that while at the same time forming new beliefs in response to my current evidence (say, the belief that 89 is a prime number), I will face a similar normative tension.

However, while the possibility of this more general kind of tension is interesting in its own right $^{6}$, what makes the tension between epistemic and zetetic norms particularly troublesome, according to Friedman, is that it points to an incoherence within epistemic normativity itself. This is because the zetetic norm of inquiry itself seems like a distinctively epistemic norm: 'it's the sort of norm the conforming to which makes for good inquiry; it's a norm that rational subjects in pursuit of knowledge and understanding are going to conform to' (Friedman 2020: 505). We are used to tension between the epistemic and the practical. It is more troublesome if there is tension within epistemic normativity itself. In the above example of a conflict between epistemic and

\footnotetext{
${ }^{4}$ The example has been modified slightly for my purposes.

${ }^{5}$ Exactly how the zetetic norms might have this implication is a question that I will take up in the next section.

${ }^{6}$ For discussion, see e.g. Reisner (2008; 2009), Berker (2018), and Steglich-Petersen \& Skipper (2019).
} 
practical norms, we might rest content with saying that, although you are epistemically permitted to form the belief that 89 is a prime number, doing so is practically impermissible in light of your duty to save the drowning child. But if the zetetic norm of inquiry is itself an epistemic norm that can conflict with other epistemic norms, it becomes unclear what you are permitted to do or believe epistemically in the first place.

The tension between the zetetic norms and the familiar epistemic norms leaves us with a set of options. One option is to fall back on the orthodox view defended by Kelly (2003), and insist that the zetetic and evidential norms belong to separate normative domains. Although this option is not without attraction, Friedman points out that it is beset with difficulty. One difficulty is that conflicting normative verdicts will remain, even if these verdicts now belong to separate normative domains. The existence of these conflicts would cast doubt on the normative force of epistemic norms. If a belief being permissible by the epistemic norms does not allow us to infer that the belief is permissible all-things-considered, it is not clear what force the permission has in the first place. Another difficulty is that it would become harder to see what grounds the epistemic norms, if they are not the sort of norms that bind us as rational inquirers in pursuit of knowledge and understanding. Why should we care about conforming to the epistemic norms, if not because of our interest in finding out the truth about questions that matter?

If we find these considerations persuasive, and agree with Friedman that the zetetic and epistemic norms must belong to the same normative domain, we face another set of options: we can either choose to accept that this domain frequently issues incoherent normative verdicts; or we can revise our understanding of either or both sets of norms so as to make them cohere with each other. As already mentioned, the first of these options does not seem very attractive. We can perhaps live with conflict between the verdicts of separate normative domains, but it is harder to live with the possibility of it being both permissible and impermissible to $\phi$ within one and the same normative domain. So, the most promising way forward is to rethink the contents of either the zetetic or the evidential norms, or both.

Like Friedman, I think that the most promising way to resolve the tension is to revise the orthodox understanding of the epistemic norms governing belief. Although I will suggest some modifications to Friedman's instrumentalist norm of inquiry, I think that the widely accepted understanding of inquiry as an aim-directed activity governed by instrumental norms and reasons is basically correct. But why think that it is our understanding of the epistemic norms that is in need of revision, and not our understanding of the norm of inquiry? I have already hinted at two arguments to this effect from Friedman. One argument is theoretical. The norm of inquiry is intuitively well motivated - it is not hard to understand from where it gets its normative grip on 
us. We are often interested in - and have good reason to - pursue knowledge and information about particular matters and questions, and this obviously puts normative pressure on us to take effective means to achieving this. The evidential norms, on the other hand, have often been seen as standing in need of explanation and motivation. This is evidenced by the large philosophical literature devoted to the question: what gives epistemic norms their binding normative force? And by the significant disagreement over the correct answer. ${ }^{7}$

Another argument is by example. Friedman has presented a case of a conflict between the zetetic and epistemic norms, where it seems most plausible that the zetetic norms should prevail. In the Chrysler Building case, it seems plausible that I ought to focus on the task of counting instead of becoming distracted by forming random but evidentially well-supported beliefs. Can we think of examples where intuition draws us in the other direction, i.e. where the verdicts of the epistemic norms should intuitively trump the verdicts of the zetetic norms? On the face of things, yes. Suppose that the only question I want to figure out is exactly how many leaves of grass there are on my lawn. I don't have any good reason to want this, but I nevertheless do. The only way of figuring this out is by counting the leaves of grass, and doing so requires considerable care and attention, which, as in Friedman's example, would be impossible if I were also forming beliefs in response to the rest of my evidence. Nevertheless, given the pointlessness of my inquiry, I might seem better off forming other beliefs, and thus frustrate my attempt to count the leaves of grass. ${ }^{8}$

Although this may seem like a case of the epistemic norms trumping the zetetic norms, I think that this appearance is misleading. Two features of the case stand out. The first is that there is no good reason in this case to engage in the inquiry - there is no good reason to figure out how many leaves of grass there are on my lawn. I may want to figure this out. But that in itself doesn't seem to create normative pressure to engage in inquiry (I will return to this point in $§ 3$ ). So, it is unclear that there is an obligation to take steps of inquiry for the epistemic norms to trump. Had there been a good reason to figure out how many leaves of grass there are, it would again seem plausible that I ought not to let myself get distracted by forming other beliefs. The second feature of the case that stands out, is that our verdict should depend on the contents of the distracting beliefs. If these beliefs concern something that is as pointless to concern oneself with, as the number of grass leaves, it again becomes unclear that I should let myself get distracted. For example, I shouldn't necessarily let myself get distracted by evidence about the number of clover plants on my lawn. But if that is the case, the example no longer speaks in favour of revising the

\footnotetext{
7 For a helpful overview and discussion of the main prevailing approaches to epistemic normativity, see Hazlett (2013: Part II).

8 This case is inspired by Rawls' famous counterexample to desire-based theories of well-being (Rawls 1971: 432).
} 
zetetic norm instead of revising the epistemic norms, since it isn't a case of a purely evidential considerations overruling the verdicts of the zetetic norms.

Although I don't take these arguments to be conclusive, ${ }^{9}$ I thus side with Friedman in leaning towards resolving the tension between epistemic and zetetic norms, by revising the former, not the latter. But how can we ensure that such a revision would not just result in new forms of tension between the revised norms? An attractive way of ensuring this would be by deriving the epistemic norms from the zetetic norms of inquiry, or from any more fundamental principle that the zetetic norms themselves flow from. We would then end up with what Friedman calls a 'zetetically grounded' account of epistemic norms. It is such an account I set out to develop and motivate in the following sections.

\section{Inquiry and Instrumental Transmission}

We can begin by considering Friedman's proposal for the central norm of inquiry, named the 'Zetetic Instrumental Principle' or 'ZIP' (Friedman 2020: 503):

ZIP: If one wants to figure out $Q^{\text {? }}$, then one ought to take the necessary means to figuring out $Q^{\text {? }}$

This is an instrumental norm which takes us from wanting to achieve a certain aim to an obligation to take the means that are necessary for achieving that aim. I will follow Friedman in taking the characteristic aim of inquiry to be that of figuring out the answer to some question Q? (What kind of tree is that? Why is my friend behaving in this way? Is justified true belief knowledge? Etc.). Friedman uses 'figuring out' as a generic placeholder for the state we aim to bring ourselves into in when we inquire in a question. A minimal understanding of this state would be as true belief. The aim of inquiry, then, would be to come to believe the true proposition that is the answer to the question one wants to figure out (That tree is an elm tree! My friend is behaving this way because she is in love! Justified true belief is not knowledge!). Some authors have proposed stronger epistemic conditions than mere true belief, with knowing the answer being the strongest such proposal. ${ }^{10}$ In the following, I will work with the simple account, identifying the aim of inquiry with believing the true answer to the question of the inquiry, but I suspect that my proposal could be fleshed out using epistemically stronger versions of the aim of inquiry as well.

\footnotetext{
${ }^{9}$ For a recent argument that the tension between epistemic and zetetic norms should not lead us to revise either set of norms, see Thorstad (forthcoming).

${ }^{10}$ For defenses of knowledge as the aim of inquiry, see Kelp (forthcoming a; b; 2021; 2014).
} 
Like most philosophical principles, ZIP is of course a bit of an idealisation. For example, inquiry does not always seem to be guided by determinate questions, but can instead be guided by a more general curiosity about some phenomenon that one is not yet in a position to ask determinate questions about. What I am most interested in here, however, is the form and normative import of ZIP. As Friedman notes (2020: 528), a potentially controversial aspect of ZIP is that it is a so-called 'narrow-scope' rather than a 'wide-scope' instrumental norm. That is to say, the normative requirement predicated by the norm takes a narrow scope in ranging over the consequent clause of the norm, rather than a wide scope in ranging over the whole conditional clause. ZIP is thus an instance of the following general narrow-scope principle, which we can contrast with its wide-scope cousin below:

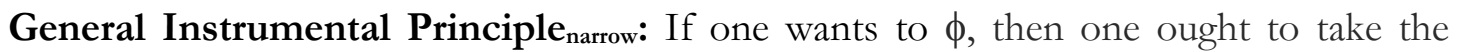
necessary means to $\phi$-ing

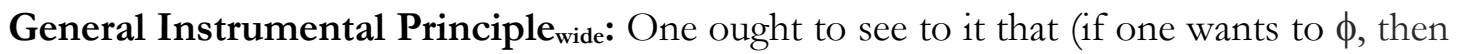
one takes the necessary means to $\phi$-ing)

What is important to note about these principles is that while the narrow-scope version makes it possible to detach an obligation to take the necessary means whenever one satisfies the antecedent clause of wanting the aim, the wide-scope version does not allow this. The wide-scope version demands that one makes the whole conditional true, but that can be achieved either by taking the means, or by not wanting the aim, and the principle is silent on which of these options one ought to take.

The possibility of tension between epistemic norms and the norm of inquiry is most salient under the assumption that the norm of inquiry is a narrow-scope norm, as suggested by Friedman. If wanting to figure out some question allows the detachment of an obligation to take the necessary means to that, it also allows the detachment of an obligation not to do anything that would prevent one from taking the necessary means. If forming some belief during the course of inquiry will prevent one from taking the necessary means to the aim of inquiry, the narrow-scope norm of inquiry thus forbids one from forming that belief, even if the belief is permitted by the epistemic norms. Hence the possible conflict pointed out by Friedman. If the norm takes a wide-scope form, on the other hand, the possibility of such conflict is not as straightforward. Suppose that only a wide-scope version of ZIP was true. I would then be forbidden from at once wanting to figure out some question, and forming certain beliefs that would prevent me from taking the necessary 
means to figuring out the question, even if those beliefs are permitted by the epistemic norms. But for all that a wide-scope version of ZIP says, the conflict could be resolved by ceasing to want to figure out the question. There would thus be a way to resolve the normative conflict without violating either norm.

However, the narrow-scope principle that ZIP exemplifies is not very plausible - one cannot create an obligation to take the necessary means to an aim merely by wanting the aim. There are possible aims that we have no reason to bring about, and we do not get such reasons simply by wanting or intending those aims. ${ }^{11}$ Friedman is aware of this problem (2020: 528), but notes that even if wanting to figure out a question cannot by itself create an obligation to take the necessary means, and we have to settle for a wide-scope version of ZIP, we sometimes have excellent reason to want to figure out a question, and, at least in such cases, the wide-scope norm plausibly allows detaching an obligation to take the necessary means, thus recreating the conflict of norms. But this might also be taken to suggests that Friedman's central observation about the possibility of normative conflict is in fact better captured by understanding the norm of inquiry as an instance of a subtly different kind of instrumental principle, namely the so-called transmission principle for instrumental reasons.

The transmission principle aims to capture the phenomenon that when we have reason for some action, this is often because that action is a means for something else that we have reason to do or achieve. For example, I can have reason to quit smoking because this is a means to something else that I have reason to achieve: not getting cancer. Or I can have reason to book a table in advance at my favourite restaurant because this is a means to something else that I have reason to achieve: getting a table. In contrast to the instrumental principles considered above, the transmission principle does not claim that wanting or intending an aim can by itself create a reason or an obligation to take means, or that certain combinations of attitudes are forbidden. Instead, it aims to capture the much less controversial idea that when we have reason to pursue an aim, that reason can transmit to the means. Another contrast to the above instrumental principles, is that the transmission principle affords the possibility of reasons to take means, even when we do not want to pursue the relevant aim, namely when we have reason to pursue the aim. This is clearly an advantage. I can have reason to pursue aims despite not wanting to pursue them. And if that is the case, I can also have reason to take means to those aims. Such cases are also plausible when it

\footnotetext{
11 This argument against narrow-scope principles of instrumental rationality is known as the 'bootstrapping problem' (Bratman 1981). This has often been taken to support a wide-scope interpretation of instrumental rationality, e.g. by Darwall (1983), Broome (1999), and Wallace (2006). For criticism of the wide-scope interpretation, see e.g. Setiya (2007), Bedke (2009), Schroeder (2009), and Kiesewetter (2017).
} 
comes to inquiry. For example, I can have reason to inquire into whether the staff meeting starts at $3 \mathrm{pm}$, and thus have reason to take means to answering that question, even if I don't want to.

As one would expect, a number of proposals for plausible transmission principles are competing in the literature, and I cannot enter into a detailed discussion of their relative virtues here. 'Conservative' principles state that reasons transmit from aims to the means that are necessary for the aim. ${ }^{12}$ However, while it may be plausible that reasons transmit to necessary means, reasons also seem to transmit to non-necessary means. Often, when we have reason to pursue some aim, there will be many different ways of achieving that aim, but in that case, none of those different ways will be necessary for the aim. For example, I might achieve relief from a tooth-ache by having a filling, or alternatively by having the tooth pulled out, or alternatively by drinking a bottle of whisky. Indeed, for many of the possible aims that one can adopt, it is hard to think of any means that would be strictly speaking necessary. Nevertheless, it seems that we can have reason to take means to such aims by virtue of having reason to pursue the aim. This suggests that we should adopt a more 'liberal' transmission principle that allows reasons to transmit from aims to any of the means that would help bring about the aim. ${ }^{13}$ It is a principle of this sort that I will rely on in the following. ${ }^{14}$

In addition to capturing the idea that one's reasons to take means are transmitted from one's reasons to pursue the relevant aim, our transmission principle should ideally also capture the idea that the strength of one's reasons to take means depends partly on the strength of one's reasons to pursue the aim, and partly on how likely the means are to help achieve the aim. That the strength of our reasons to take means depends on the strength of our reasons to pursue the aim seems obvious. For example, other things being equal, I have more reason to take means to avoid losing my job, than I have to take means to avoid losing my place on the Wordfeud leaderboard, since it is much more important for me not to lose my job. Only slightly less obviously, the strength of

\footnotetext{
${ }^{12}$ For versions of conservative transmission principles, see e.g. Darwall (1983: 16), Setiya (2007: 660), Bratman (2009: 424), Schroeder (2009: 234), Way (2010: 225), Scanlon (2014: 85), and Kiesewetter (2015).

${ }^{13}$ Defenses of or reliance upon liberal transmission principles can be found in Raz (2005), Bedke (2009), Way (2012), Schroeder (2007; 2009), and Kolodny (2018).

14 Although popular, liberal transmission principles are not without detractors. The most common objection is that such principles would allow the transmission of reasons to means that are highly inefficient or very objectionable in other respects. For example, it would allow my reason to become rich to transmit to the highly inefficient means of taking a degree in philosophy; and, to repeat a famous example, it would allow my reason to avoid a feeling of hunger to transmit to the very objectionable means of killing myself (Broome 2005: 7). Some authors have a strong intuition that no reason whatsoever can transmit to such means, and that defenders of the liberal transmission principle must at the very least explain away this intuition. A common strategy here appeals pragmatic considerations: when calling something a 'reason', it is pragmatically implied that it is not massively outweighed by other considerations. This strategy is taken by Schroeder (2005; 2007), Raz (2005), Bedke (2009), Way (2012), and Kolodny (2018). Speaking for myself, I don't share the intuition that there is no transmitted reason to take the means in the mentioned examples, and hence I don't think that there is an intuition to be explained away. Motivating this, however, would take us too far afield. For a recent critical discussion of liberal transmission principles, see Kiesewetter and Gertken (forthcoming).
} 
the transmitted reason to take the means depends on how likely the means are to help achieve the aim. Making an effort with my teaching, and regularly watering the flowers in the department lounge, are plausibly both acts that could help me keep my job. But the former act is much more likely to help me keep my job than the latter, and it thus seems plausible that even though both acts are possible means to the same aim, my reason to do the former is stronger than my reason to do the latter.

To capture these ideas, I will rely on the following liberal transmission principle, inspired by Niko Kolodny's 'General Transmission’ principle (2018), but simplified slightly for our purposes:

General Instrumental Transmission: If there is reason for one to pursue aim A, and there is positive probability conditional on one's $\phi$-ing, that one's $\phi$-ing helps bring about A, then that is a reason for one to $\phi$, the strength of which depends on the reason for one to pursue $\mathrm{A}$ and the probability.

Some comments are needed to clarify the content of the principle. First, the principle makes no assumptions about the kinds of reasons for pursuing aims that can transmit to means, and as such, it is compatible with many different normative theories, e.g. whith reasons being value-based, based on rules, desires, or something else. In principle, it is thus also compatible with holding, as Friedman does, that wanting an aim can give one reason to take means to it. Second, the condition on means that they 'help bring about' the aim should not be construed too narrowly. In particular, it should not be understood as restricted to causing or being part of a cause of the aim becoming realised. It can also amount to constituting, satisfying preconditions of, preventing preventers, and the like, so long as these conditions play a part in bringing about the aim (Kolodny 2018). This will become important later on. Third, the principle cashes out the relevant means' degree of effectiveness in terms of how taking the means would affect the probability of the means helping to bring about the aim. The relevant kind of probability at play here is epistemic probability. ${ }^{15}$ So, when we are to determine whether a reason to pursue an aim A is transmitted to a possible means $\phi$, we have to consider the probability of $\phi$-ing helping bring about A, conditional on one's total evidence plus the hypothetical supposition of one's $\phi$-ing. To give an example, if I am to determine

\footnotetext{
15 Why should the relevant probability not be identified with objective chance? Partly, this choice reflects a general commitment to a kind of 'perspectivism' about one's possessed or available reasons (for both actions and beliefs) as being sensitive to one's evidence. It may make sense to also operate with an objective sense of reasons that exist independently of one's evidence. Such reasons, however, would not have direct implications for what one ought to do. For recent defenses of perspectivism, see e.g. Kiesewetter $(2017$; 2018) and Lord (2018).
} 
whether my reason to pursue the aim of getting a promotion transmits to the possible means of working longer hours, I have to add the supposition of me working longer hours to my existing relevant evidence (for example about my department culture, the sentiments of my department chair, the official guidelines for promotion, my ability to work effectively for a long time, and the like), and gauge if there is positive (i.e. non-zero) probability of me working longer hours helping me to get a promotion. If there is positive probability, at least some reason is transmitted to working longer hours, and the strength of the reason will depend partly on how high the probability is. ${ }^{16}$

If we take this general transmission principle, rather than the generalised version of ZIP, as our basis for understanding the instrumental reasons bearing on us as inquirers, we can insert the appropriate terms to arrive at the following principle for zetetic reasons, which I propose as a replacement of ZIP:

Zetetic Instrumental Transmission (ZIT): If there is reason for one to pursue the aim of figuring out $Q^{\text {? }}$, and there is positive probability conditional on one's $\phi$-ing, that one's $\phi$-ing helps figuring out $Q$ ?, then that is a reason for one to $\phi$, the strength of which depends on the reason for one to pursue the aim and the probability.

A notable difference between this norm, and the ZIP-norm favored by Friedman, is that it yields reasons rather than obligations to take means as its output. This seems like a further advantage of ZIT over ZIP, since it allows the principle to cover cases where there is reason to inquire without there being an obligation to inquire, for example because the reasons are weak or outweighed by other reasons. For example, as I write, I have some reason to inquire into the current score of a local football match of vague interest to me, but I clearly have no obligation to do so. Some might wonder whether this in itself ameliorates the seeming tension between epistemic and zetetic norms. After all, if reasons can be outweighed, conflicts between epistemic and zetetic norms might be resolved by weighing the zetetic reasons against the epistemic ones. But that overlooks that the reasons to take the means can be decisive. If there is decisive reason to pursue the aim, and it is

\footnotetext{
16 Why not simply let the strength of the transmitted reason depend on the probability of the aim being realised conditional on taking the means, rather than letting it depend on the probability of the means helping to bring about the aim conditional on taking the means? Kolodny's rationale for this rests on cases of actions that raise the probability of an aim being realised without thereby being means to them (see Kolodny 2018: \$1). For example, a boxer who aims to land a punch might grit his teeth every time he throws a punch, in which case the probability of landing a punch conditional on his gritting his teeth will be higher than otherwise. Note, however, that even on Kolodny's account, transmitted reasons for means will be stronger, the more likely the means are to achieve the relevant aims, since, trivially, the more likely it is that a means will achieve an aim, the more likely it will be that the means help bring about the aim. In what follows, I will thus largely ignore this complication, and simply consider whether the relevant means make achieving the aim more likely. For discussion and an alternative probabilistic transmission principle, see Bedke (2017).
} 
sufficiently likely that some means will result in the aim, and no other means are available, it can plausibly be the case that the reason to take the means is also a decisive reason, and hence that you ought to take the means. It seems possible for this to hold true for our reasons to take acts of inquiry, in which case the move from ZIP to ZIT does not by itself remove the possibility of the problematic tension within epistemic normativity.

To illustrate, consider how the principle would apply in Friedman's example. Suppose that there is reason for me to figure out how many windows there are in the Chrysler Building. That is to say, there is reason for me to pursue the aim of coming to believe the true answer to the question: How many windows are there in the Chrysler Building? Various things that I can do will increase the probability of me achieving such a true belief. For example, if I have a colleague whose hobby is to study famous buildings, asking him would increase the probability of coming to a true belief. The strength of the reason I thereby gain is determined by two factors: the strength of the reason I had to figure out the question in the first place, and the probability that asking my colleague will help me to learn the true answer. In most cases, different means can combine in different ways to bring about the aim, and often none of the means will be necessary. In the case at hand, I could also have typed the question into a search engine, or consulted a lexicon. But we can also imagine cases where some means are necessary for bringing about the aim. For example (although somewhat far-fetched), we can imagine that in Friedman's example, the only way of figuring out how many windows there are in the Chrysler Building, is to count them myself. In such cases, if the reason to pursue the aim is a decisive reason, i.e. a reason that makes it the case that one ought to pursue the aim, then it will also be the case that one ought to take the necessary means. So, although the principle has reasons rather than obligations as outputs, it will still be possible for the kind of normative tension described by Friedman to obtain.

Obviously, much more could said to motivate and explicate this account of zetetic reasons for acts of inquiry. ${ }^{17}$ For now, however, I will return to the question of how these reasons relate to epistemic reasons for belief. As I will now argue, the relationship is very close. In fact, epistemic reasons for belief can be understood as a special case of the reasons that are transmitted from the aim of inquiry.

\footnotetext{
17 Some readers might worry about potential counterexamples where there is reason to figure out a question, and positive probability that some action will help figuring out the question, but where there intuitively is no transmitted reason to perform that action. For example, I might have reason to figure out whether I can complete a strenuous race, and be aware that injuring my foot would ensure that I will not be able to complete the race. In that case, injuring my foot would help me figuring out if I can complete the race. But do I thereby have reason to injure my foot? It seems not. What is peculiar about this case, I take it, is that I bring myself into a position of being able to correctly answer the question by causally affecting what the correct answer is. If we wish to exclude the possibility of transmission of reasons to such acts, we can include an amendment to the principle to that effect, but I will not attempt to do so here. I am grateful to an anonymous reviewer for bringing up this potential counterexample.
} 


\section{Zetetically Grounded Reasons for Belief}

We have already seen how reasons to pursue the aim of figuring out the answer to a question can transmit to various acts of inquiry that stand to help bringing about that aim. Most commonly, these acts help bring about the aim by causing one's epistemic condition to change in ways that make achieving the aim more likely. But, as mentioned above, 'helping to bring about' should not be construed too narrowly. And in fact, the reasons to pursue the aim of inquiry also seem to transmit to a means that will constitute the fulfilment of the aim, rather than play a causal role of its realisation. This constitutive means is simply that of believing the proposition that is the true answer to the question one wants to answer. So, suppose again that there is reason for me to pursue the aim of coming to believe the true answer to the question: How many windows are there in the Chrysler Building? And suppose that the true answer is: There are 3.862 windows in the Chrysler Building. In that case, believing that there are 3.862 windows in the Chrysler Building will constitute the fulfilment of the aim. The reason that I have to pursue the aim will thus transmit to that belief whenever (and partially to the degree that) there is positive probability that the belief will constitute fulfilling the aim. More generally, if the aim of inquiry is that of figuring out the

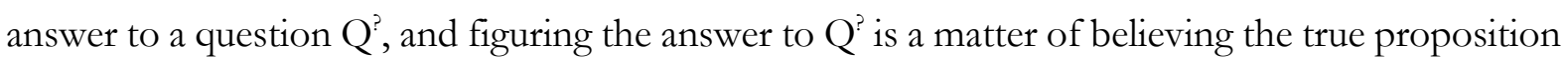
that is the answer to $\mathrm{Q}$, then believing $\mathrm{p}$ is a constitutive means to the aim of inquiry with respect to $\mathrm{Q}$ ? whenever $\mathrm{p}$ is in fact the true answer to $\mathrm{Q}$ ?

To clarify this idea of zetetic reasons transmitting to beliefs, consider the following spelledout version of ZIT, where the aim of inquiry is identified with believing the true answer to the relevant question $Q^{\text {? }}$, and the relevant means is specified to be a belief:

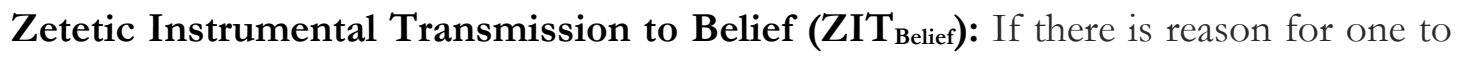
pursue the aim of coming to believe the true answer to question $Q^{\text {? }}$, and there is positive probability conditional on one's believing $\mathrm{p}$, that believing $\mathrm{p}$ helps bring about believing the true answer to $\mathrm{Q}$, then that is a reason for one to believe that $\mathrm{p}$, the strength of which depends on the reason for one to pursue the aim and the probability.

Suppose that there is reason to come to believe the true answer to $\mathrm{Q}^{\text {? }}$ (reason, that is, to pursue the aim of inquiry with respect to $Q^{2}$ ), and focus on the second antecedent clause: the probability conditional on one's believing $\mathrm{p}$ that this helps bring about believing the true answer to $\mathrm{Q}$ ? There are a number of ways that believing some proposition could help bring about believing the true answer to a question. Some of these ways are causal. Perhaps having a true belief about the location of the library would increase the probability of finding information pertinent to a question, and 
hence of coming to believe the true answer to that question. But, if $\mathrm{p}$ is itself the true answer to $\mathrm{Q}$, believing $\mathrm{p}$ will constitute believing the true answer to $\mathrm{Q}$ ? Hence, if there is positive probability that $\mathrm{p}$ is the true answer to $\mathrm{Q}$, then there is positive probability that believing $\mathrm{p}$ will help bring about, in the sense of constituting, believing the true answer to Q? This would mean that the second antecedent clause of $\mathrm{ZIT}_{\text {Belief }}$ will be satisfied, and hence that there will be transmitted reason to believe that $\mathrm{p}$.

Transmission of reasons from an aim to a means that is constitutive of the aim might at first seem somewhat suspect, but on reflection, such transmission seems commonplace. ${ }^{18} \mathrm{~A}$ constitutive means to an aim can be understood as a particular way of realising the aim, or as a part of a particular realisation. As Ausonio Marras (2003) notes, what might lead some to think that constitutive means are not really means is that they will be token-identical to the aim, and it can seem artificial to say that one $\phi$ s in order to $\psi$, when $\phi$-ing and $\psi$-ing are one and the same thing. But token-identity does not imply type-identity, and it seems perfectly natural to say that a means can be token-identical to an aim, as long as they are not type-identical. Suppose, for example, that my doctor has made me realize that I ought to exercise. Jogging is particular way of exercising, and if I go jogging, I am, thereby, exercising. Nevertheless, it would make sense to claim that I jog in order to exercise, and that my reason to exercise transmits to jogging. Or suppose that I have reason to take an education that will make it easy to find employment. There are many different educations that will make it easy to find employment, and taking each one of them would constitute taking an education that will make it easy to find employment. Suppose that an education in computer science is one of them. Whatever other reason I might have to study computer science, my reason to take an education that makes it easy to find employment will thus transmit to studying computer science.

If reasons for pursuing the aim of figuring out a question transmit to the belief that is in fact the true answer to the question, wouldn't that make other acts of inquiry obsolete? After all, if a true answer exists, believing that answer will guarantee the fulfilment of the aim, so there would be no need for any other means that might help bring about the aim - there will always be a maximally effective means available. But this ignores the kind of probability at play in instrumental transmission. Even if a true answer to the question exists, the answer may be improbable given one's evidence. For example, even if the Chrysler Building in fact has 3.862 windows, it may not be very probable on my evidence that it does. If so, I will not have a very strong reason to believe

\footnotetext{
${ }^{18}$ The idea of constitutive means harks back at least as far as Aristotle's discussion of activities that are constitutive rather than causal means for eudaimonic well-being (Aristotle 1984). In a more recent context, the idea is endorsed by e.g. Kolodny (2018) and Kiesewetter \& Gertken (forthcoming). For critical exchange, see Audi (2001) and Marras (2003).
} 
that proposition, even if I have a strong reason to figure out how many windows there are in the building. That is why we must engage in inquiry - to improve our epistemic position to a point where the evidence makes an answer sufficiently likely for belief. The same point applies, of course, to any other means. There may exist a possible means to an aim, that is guaranteed to achieve the aim, but nevertheless fail to be supported by a reason transmitted from the aim, because one's evidence does not make it sufficiently probable that the means will help achieve the aim. Suppose, for example, that ingesting a particular pill would in fact cure a serious disease that I suffer from, and that I have reason to try to cure. Do I thereby have a reason to take the pill, according to the general transmission principle? Only if my evidence makes it sufficiently likely that the pill will cure me. So, there is nothing peculiar about the existence of a maximally effective means that one nevertheless does not have reason to take, because it isn't sufficiently likely on one's evidence that it is in fact maximally effective.

It seems plausible, then, that reasons to pursue the aim of inquiry can transmit to particular beliefs, and not just to acts of inquiry. What is the character of these transmitted reasons for belief? In particular, how do they relate to epistemic reasons for belief? Here is a radical proposal for a zetetically grounded theory of epistemic reasons: epistemic reasons for belief are simply a subclass of the reasons that are transmitted from the aim of inquiry to the means that will promote that aim, namely that subclass that speaks in favor of beliefs in virtue of the beliefs being likely to constitute the aim of inquiry. Epistemic reasons, that is, are a subclass of zetetic reasons. The theoretical advantages of this proposal should be obvious, and I will return to discuss them later on. Most importantly, it delivers the desired grounding of epistemic reasons in zetetic reasons. But for now, let us focus on the obstacles to the proposal.

An immediate obstacle to identifying epistemic reasons with reasons transmitted from the aim of inquiry, is that, on the face of things, we seem to have epistemic reason to adopt many more beliefs than can be accounted for by the questions we have reason figure out. At every moment, there are countless propositions that I have excellent evidence for, but that I do not believe. For example, as I am sitting here, I become aware that there are less than ten letters in the name of the computer on which I am currently typing. It might seem plausible that this gives me reason to believe that there are less than 12 letters in the name (and less than 13 letters, and so on). But on the current proposal, for the evidence to be an epistemic reason for me to believe that there are less than 12 letters in the name of the computer, there must exist some question that I have reason to figure out, such that believing that proposition is likely to constitute believing the true answer. And so on for any other proposition that I have evidence for. But is that really plausible? I think that it is. 
Note first that, trivially, for any proposition $\mathrm{p}$, there will exist at least one question $\mathrm{Q}^{\text {? }}$, such that believing $\mathrm{p}$ or its negation not-p will constitute believing the true answer to $\mathrm{Q}^{\text {? }}$, namely the question: whether $p .{ }^{19}$ If $\mathrm{p}$ is true, and you believe that $\mathrm{p}$, you will thereby believe the true answer to the question whether $p$. Although trivial, this observation allows us to reformulate ZIT $_{\text {Belief }}$ in the following way, that makes transparent for any proposition that we might have evidence for, at least one possible inquiry-aim from which a reason could be transmitted:

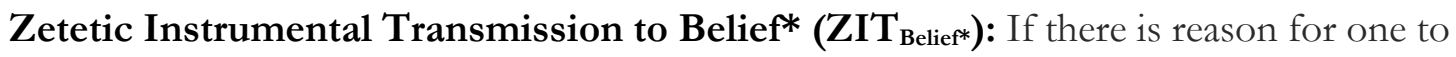
pursue the aim of coming to believe the true answer as to whether $\mathrm{p}$, and there is positive probability conditional on one's believing $\mathrm{p}$, that believing $\mathrm{p}$ helps bring about believing the true answer as to whether $\mathrm{p}$, then that is a reason for one to believe that $\mathrm{p}$, the strength of which depends on the reason for one to pursue the aim and the probability.

Inquiries that aim to figure out questions that do not have the simple whether $p$ form, such as the question of how many windows there are in the Chrysler Building, might be understood as aiming to settle the truth of each of the propositions that could constitute possible answers. ${ }^{20}$ So, when I aim to come to a true belief as to how many windows there are in the Chrysler Building, I aim to come to a true belief as to whether there is one window, whether there are two windows, ... whether there are 3.862 windows, and so on. This does not imply, of course, that one aims to figure out these questions in a piecemeal manner, or that one must have all of these questions at the forefront of one's mind when trying to figure out how many windows there are in the building. Figuring out any one of these more specific questions will mean that one has figured out the rest (if there is only one window, there aren't two, etc.). But it does imply that aiming to figure out the general question will carry with it an implicit aim to figure out the more specific ones.

So, it is plausible that for any proposition that I might have evidence for, there exists a possible question, and hence a possible inquiry-aim, from which a reason could be transmitted. But this is only half the answer to the objection we are currently considering. We must also

\footnotetext{
19 This idea mirrors (but is not equivalent to) the popular idea that knowing-wh (e.g. knowing what, knowing whether, knowing who, etc.) is a matter of knowing that $\mathrm{p}$, where $\mathrm{p}$ is the true answer to the indirect question embedded in the wh-clause. For example, on this account, if the game begins at $4 \mathrm{pm}$, knowing what time the game begins is a matter of knowing that the game begins at 4pm. For discussions of this account, see Hintikka (1975), Lewis (1982), Higginbotham (1996), Schaffer (2007), and Steglich-Petersen (2014).

20 This reflects the common idea in formal semantic theories of questions that the meaning of a question is determined by the set of propositions that could constitute possible answers. So, the meaning of the question 'How many windows are there in the Chrysler Building' is determined by the set of propositions [There is one window in the Chrysler Building; There are two windows ... etc.], and an interest in the question thus implies an interest in each of the propositions constituting its meaning. For this theory, see Hamblin (1973) and Karttunen (1977).
} 
consider whether it is plausible that whenever the evidence gives us reason to believe a proposition, we in fact do have reason to inquire into the relevant question.

In order to answer this, it pays to note that what we have arrived at with above instance of the transmission principle, is identical to the central principle of the transmission-based version of epistemic instrumentalism that I have defended elsewhere. ${ }^{21}$ Like other versions of epistemic instrumentalism, this one also faces the well-known and much discussed objection known as the 'too few reasons' objection. ${ }^{22}$ This is the objection, roughly, that if we make epistemic reasons for believing $\mathrm{p}$ dependent on whether the epistemic agent aims at coming to believe the truth as to whether $\mathrm{p}$, the account will fail to generate epistemic reasons whenever the epistemic agent does not have that aim - the account will thus generate too few reasons. However, the transmissionbased account enjoys a dialectical advantage over traditional forms of instrumentalism with respect to this objection. Whereas traditional forms of instrumentalism make epistemic reasons depend on the contingent aims of epistemic agents (does the epistemic agent in fact aim or desire to believe the truth with respect to p?), the transmission-based account makes epistemic reasons depend on whether the epistemic agent has reason to pursue the aim of believing the truth as to whether $\mathrm{p} .{ }^{23} \mathrm{It}$ is thus possible on the transmission-based account for an epistemic agent to have epistemic reason to believe that $\mathrm{p}$, even if the she happens not to care about believing the truth as to whether $\mathrm{p}$. This makes it dialectically tricky for opponents to think of counterexamples, where the account fails to predict an existing epistemic reason. In any such counterexample, there must be an evidence-based reason for a person to believe that $\mathrm{p}$, but no reason for that person to come to (or have) a true belief as to whether p. But presumably, on any account of epistemic reasons, evidence counts in favor of believing $\mathrm{p}$ in virtue of making it sufficiently likely that one will believe the truth by believing $\mathrm{p}$. So how could evidence for $\mathrm{p}$ be a reason for believing $\mathrm{p}$ in virtue of making it likely that one will thereby believe $\mathrm{p}$ truly, if there is no reason to come to a true belief as to whether $p ?^{24}$

\footnotetext{
${ }^{21}$ Steglich-Petersen (2018) and Steglich-Petersen \& Skipper (2019; 2020). See also Steglich-Petersen (2006; 2009; 2011; 2013) for earlier versions.

${ }^{22}$ For versions of this objection, see e.g. Kelly (2003), Schroeder (2007), and Côté-Bouchard (2015).

${ }^{23}$ For traditional forms of instrumentalism, that take the aims of believers rather than reasons to pursue aims as the normative source of epistemic reasons, see e.g. Quine (1967), Foley (1987), Laudan (1990), Kornblith (1993), Nozick (1993), and Papineau (1999). Some instrumentalists appeal, like I do, to aims that one has reason to have, but do not spell out this idea in terms of the transmission principle, e.g. Grimm (2009) and Cowie (2014). ${ }^{24}$ What is the relationship between the proposed account of epistemic reasons and evidentialism about epistemic reasons? If we take evidentialism to be the strict view that epistemic reasons consist of evidence and nothing else, then the proposed account is not a version of evidentialism, since it makes epistemic reasons depend partly on reasons for pursuing true beliefs, and these reasons are not evidential. The account seems, however, to retain some of the spirit of evidentialism, by making evidence for $\mathrm{p}$ necessary for having epistemic reason to believe that $\mathrm{p}$. Furthermore, although I don't myself hold that view, the account is compatible with thinking that we have reason to pursue true beliefs about all propositions, in which case the account becomes extensionally equivalent to the stricter version of evidentialism, in the sense of implying the same epistemic reasons.
} 
Much more could be said on this issue, and there are of course other possible objections to, as well as virtues of, this brand of epistemic instrumentalism, some of which I have discussed elsewhere. ${ }^{25}$ But the purpose of the present paper is not defend instrumentalism. It is rather to show how instrumentalism, and in particular the transmission-based version, provides a natural unification of zetetic and epistemic reasons. Given that we have reason to seek an account of zetetic and epistemic reasons that do not put them at odds with one another, this in itself should be a point in favour of instrumentalism. ${ }^{26}$

To illustrate the unification, consider how the present account would play out in the example that Kelly (2003) used to motivate the difference between zetetic and epistemic reasons. You hear a noise behind you and become interested in figuring out the question: what made that noise? We can suppose that your interest gives you reason to figure out the question, but even if you aren't in fact interested, you could have such a reason nonetheless (perhaps you are responsible for keeping intruders out of the house). This reason will now transmit both to acts of inquiry that will causally improve your chances of figuring out the question, and to beliefs that could potentially constitute having figured out the question. On your current evidence, no particular belief on the matter is very likely to constitute having figured out the question. Is it a cat? A child? An intruder? None of the options are particularly likely. Although reasons transmit to beliefs in each of these possibilities, these reasons are thus rather weak. But various acts of inquiry are supported by stronger transmitted reasons. For example, if you turn around and look in the direction of the noise, there is an excellent chance that this will help you figure out the question. Suppose you do that, and now become face to face with a cat. This obviously changes your evidential situation, to the point that there now is a belief that is very likely to constitute having figured out the question, namely the belief that a cat made the noise. The transmitted reason to adopt that belief is thus stronger, and presumably sufficiently strong that you may adopt it. ${ }^{27}$ Once you do that, the inquiry is brought to an end. Rather than involving an interplay of two fundamentally different kinds of reasons, we can thus understand this process from initial curiosity to belief as involving reasons of a single kind - instrumental reasons transmitted from the aim of inquiry - albeit in support of two different kinds of responses: acts of inquiry and beliefs.

\footnotetext{
${ }^{25}$ Among the objections: we tend to talk as if evidence in itself constitute reasons for belief, and transmitted instrumental reasons have various properties that epistemic reasons don't seem to share. Among the virtues: this version of epistemic instrumentalism explains the distinctiveness of epistemic reasons - something that other brands of instrumentalism have trouble with. Epistemic reasons are reasons that speak in favor of beliefs in virtue of the beliefs being likely to constitute the aim of inquiry. See e.g. Steglich-Petersen (2018) and Steglich-Petersen \& Skipper (2019; 2020) for discussion.

${ }^{26}$ For more general reasons to seek an account of epistemic normativity that is unified with practical normativity, see e.g. Steglich-Petersen (2018) and Rinard (2019).

${ }^{27}$ When is there sufficient reason for belief, on this understanding? That question is discussed in Steglich-Petersen \& Skipper (2020).
} 


\section{Conflicts Between Epistemic and Zetetic Reasons?}

Just because epistemic reasons are a subclass of zetetic reasons, it doesn't follow that they cannot come into conflict with one another. Such conflicts, however, should be approached the same way as conflicts between transmitted instrumental reasons in general: the reasons must we weighed against each other to determine which of the reasons are stronger.

There are several different types of possible conflicts between instrumental reasons. The most obvious source of conflict is when one has reason to pursue two aims that cannot both be realised, either because the aims themselves are incompatible, or because the only means to the two aims cannot both be taken. But conflicts can also arise when the aims merely detract from one another, or when the best means to the aims somehow limit each other. How might one's opposing instrumental reasons be weighed against each other in such cases? According to the transmission principle, the weight of any given instrumental reason is determined by the weight of the reasons one has to pursue the relevant aim, and the probability that the relevant means will help achieve that aim. Both factors should thus be taken into account when determining which instrumental reason is stronger. This also means that an instrumental reason to take a means for an aim may be outweighed by an instrumental reason for a means in pursuit of another aim, even if there is less strong reason to pursue the latter aim than the former, namely if the probability of achieving the more desirable aim is very low. And conversely, if one has very strong reason to pursue some aim, reasons for taking very improbable means may trump more certain means for other aims, that one has less strong reason to pursue. ${ }^{28}$

What happens if we apply these principles to conflicts between zetetic and epistemic reasons? Take once again Friedman's example. You have reason to pursue the aim of figuring out - urgently - how many windows there are in the Chrysler Building, and can only do so by counting them. As you do so, you acquire a wealth of evidence on other matters. But forming beliefs in response to this evidence would make it impossible to complete the count. It is clear that you should concentrate on the count - that the reasons for doing so somehow trump whatever reasons you gain from the distracting evidence. And we can now explain what this amounts to. Suppose that the evidence you accidentally gain while counting makes it very probable, among many other things, that more males than females have passed by on the sidewalk within the preceding 10 seconds. On the present account, this only amounts to a reason to believe that more males than females have passed by, provided that you have some antecedent reason to come to a true belief as to whether more males than females have passed by, and the weight of the reason to believe

${ }^{28}$ For a more comprehensive account of how to weigh instrumental reasons, see Steglich-Petersen \& Skipper (2019). 
this will be determined in part by the weight of this antecedent reason. In the present case, we can assume that the weight of this antecedent reason, if such a reason even exists, is very low. Even if there is a high probability of gaining a true belief if you do form the belief that more males than females have passed by, the weight of the transmitted reason for forming this belief will thus also be quite low. And if its weight is lower than the transmitted reason to focus on counting the windows, it will be trumped by this latter reason. By relying on the general principles for weighing transmitted instrumental reasons, we are thus able to explain the right verdict for Friedman's case.

\section{Conclusion}

Motivated by Friedman's call for a revision of our understanding of epistemic reasons to bring them into harmony with zetetic reasons, I have argued for an account of zetetic reasons as a species of transmitted instrumental reasons, and argued further that this account can be extended to encompass epistemic reasons as well. The resulting theory of epistemic reasons is, in effect, identical to an independently motivated version of instrumentalism about epistemic reasons. The upshot is, thus, that this transmission-based form of instrumentalism yields a unified understanding of zetetic and epistemic reasons. And, since the underlying transmission principle also applies to instrumental action, this unification encompasses the practical as well. I have not attempted a full defense of the underlying form of epistemic instrumentalism. However, if instrumentalism can help us resolve the apparent tension between epistemic and zetetic normativity, this should in itself count in its favor.

\section{References}

Aristotle. 1984. "Nicomachean Ethics." In The Complete Work of Aristotle, Vol. II, edited by J. Barnes. Princeton: Princeton University Press.

Audi, Robert. 2001. The Architecture of Reason: The Structure and Substance of Rationality. Oxford: Oxford University Press.

Bedke, Matthew. 2009. “The Iffiest Oughts: A Guide of Reasons Account of End-Given Conditionals." Ethics 119: 672-698.

Bedke, Matthew. 2017. "Ends to Means. A Probability-Raising Account of Means and the Weight of Reasons to Take Them." Journal of Ethics and Social Philosophy 12: 6-28.

Berker, Selim. 2018. “A Combinatorial Argument Against Practical Reasons for Belief.” Analytic Philosophy 59: 427-470.

Bratman, Michael. 1981. "Intention and Means-End Reasoning." The Philosophical Review 90: 252- 
265.

Bratman, Michael. 2009. "Intention, Practical Rationality, and Self-Governance.” Ethics 119: 411443.

Broome, John. 1999. "Normative Requirements.” Ratio 12: 398-419.

Broome, John. 2005. "Have we Reason to Do as Rationality Requires? - A Comment on Raz." Journal of Ethics and Social Philosophy 1: 1-10.

Côté-Bouchard, Charles. 2015. "Epistemic Instrumentalism and the Too Few Reasons

Objection.” International Journal of Philosophical Studies 23: 337-355.

Cowie, Christopher. 2014. "In Defence of Instrumentalism about Epistemic Normativity."

Philosophical Studies 191: 4003-4017.

Darwall, Stephen. 1983. Impartial Reason. Ithaca: Cornell University Press.

Foley, Richard. 1987. The Theory of Epistemic Rationality. Cambridge, Mass.: Harvard University

Press.

Friedman, Jane. 2018. "Junk Belief and Interest-Driven Epistemology.” Philosophy and Phenomenological Research 97: 568-583.

Friedman, Jane. 2019. “Inquiry and Belief.” Noûs 53: 296-315.

Friedman, Jane. 2020. "The Epistemic and the Zetetic.” The Philosophical Review 129: 501-536.

Friedman, Jane. Forthcoming. "Zetetic Epistemology.” In Towards and Expansive Epistemology:

Norms, Action, and the Social Sphere, edited by B. Reed \& A.K. Flowerree. London: Routledge.

Grimm, Stephen. 2009. "Epistemic Normativity.” In Epistemic Value, edited by A. Haddock, A.

Millar \& D. Pritchard. Oxford: Oxford University Press.

Hamblin, Charles L. 1973. “Questions in Montague English.” In Foundations of Language 10: 41-53.

Hazlett, Allan. 2013. A Luxury of the Understanding. On the V alue of True Belief. Oxford: Oxford

University Press.

Higginbotham, James. 1996. “The Semantics of Questions.” In The Handbook of Contemporary Semantic Theory, edited by Shalom Lapin. Oxford: Oxford University Press.

Hintikka, Jaako. 1975. "Different Constructions in Term of the Basic Epistemological Verbs: A Survey of Some Problems and Proposals." In The Intensions of Intentionality and Other New Models for Modalities. Dordrecht: Klüver.

Hookway, Christopher. 2006. "Epistemology and Inquiry: The Primacy of Practice.” In Epistemology Futures, edited by S. Hetherington. Oxford: Oxford University Press.

Hookway, Christopher. 2008. "Questions, Epistemology, and Inquiries.” Grazer Philosophische Studien 77: 1-21.

Karttunen, Lauri. 1977. "Syntax and Semantics of Questions." Linguistics and Philosophy 1: 3-44. 
Kelly, Thomas. 2003. "Epistemic Rationality as Instrumental Rationality: A Critique." Philosophy and Phenomenological Research 66: 612-640.

Kelp, Christoph. 2014. “Two for the Knowledge Goal of Inquiry.” American Philosophical Quarterly 51: 227-237.

Kelp, Christoph. 2021. Inquiry, Knowledge, and Understanding. Oxford: Oxford University Press.

Kelp, Christoph. Forthcoming a. "Theory of Inquiry." Philosopby and Phenomenological Research

Kelp, Christoph. Forthcoming b. "Inquiry, Knowledge and Understanding." Synthese

Kiesewetter, Benjamin. 2015. "Instrumental Normativity: In Defense of the Transmission Principle." Ethics 125: 921-946.

Kiesewetter, Benjamin. 2017. The Normativity of Rationality. Oxford: Oxford University Press.

Kiesewetter, Benjamin. 2018. "How Reasons are Sensitive to Available Evidence." In Normativity:

Epistemic and Practical, edited by C. McHugh, J. Way \& D. Whiting. Oxford: Oxford University Press.

Kiesewetter, Benjamin \& Jan Gertken. Forthcoming. "How do Reasons Transmit to Non-

Necessary Means?" Australasian Journal of Philosophy.

Kolodny, Niko. 2018. "Instrumental Reasons." In The Oxford Handbook of Reasons and Normativity, edited by D. Star. Oxford: Oxford University Press.

Kornblith, Hilary. 1993. "Epistemic Normativity.” Synthese 94: 357-376.

Laudan, Larry. 1990. "Normative Naturalism.” Philosophy of Science 57: 44-59.

Lewis, David. 1982. “'Weather' Report.” In Philosophical Essays Dedicated to Lennart Aqvist on his

Fiftieth Birthday, edited by T. Pauli. Uppsala: University of Uppsala.

Lord, Errol. 2018. The Importance of Being Rational. Oxford: Oxford University Press.

Maddox, Brenda. 2003. Rosalind Franklin: The Dark Lady of DNA. New York: Harper Perennial.

Marras, Ausonio. 2003. “Audi on Substantive vs. Instrumental Rationality.” Philosophy and

Phenomenological Research 67: 194-201.

Nozick, Robert. 1993. The Nature of Rationality. Princeton: Princeton University Press.

Papineau, David. 1999. "Normativity and Judgment." Proceedings of the Aristotelian Society 73: 17-43.

Quine, W.V.O. 1967. “Epistemology Naturalized.” In Ontological Relativity and Other Essays. New York: Columbia University Press.

Rawls, John. 1971. A Theory of Justice. Cambridge, Mass.: Harvard University Press.

Raz, Joseph. 2005. "The Myth of Instrumental Rationality." Journal of Ethics and Social Philosophy 1: $1-28$.

Reisner, Andrew. 2008. "Weighing Pragmatic and Evidential Reasons for Belief." Pbilosophical Studies 138: 17-27. 
Reisner, Andrew. 2009. “The Possibility of Pragmatic Reasons for Belief and the Wrong Kind of Reasons Problem.” Philosophical Studies 145: 257-272.

Rinard, Susanna. 2019. "Equal Treatment for Belief.” Philosophical Studies 176: 1923-1950.

Scanlon, T.M. 2014. Being Realistic About Reasons. Oxford: Oxford University Press.

Schroeder, Mark. 2005. "Instrumental Mythology.” Journal of Ethics and Social Philosophy 1: 1-12.

Schroeder, Mark. 2007. Slaves of the Passions. Oxford: Oxford University Press.

Schroeder, Mark. 2009. "Means-End Coherence, Stringency, and Subjective Reasons." Philosophical Studies 143: 223-248.

Schaffer, Jonathan. 2007. "Knowing the Answer." Philosophy and Phenomenological Research 75: 383403.

Setiya, Kieran. 2007. “Cognitivism About Instrumental Reason.” Ethics 117: 649-673.

Steglich-Petersen, Asbjørn. 2006. "No Norm Needed: On the Aim of Belief." The Philosophical Quarterly 56: 499-516.

Steglich-Petersen, Asbjørn. 2009. "Weighing the Aim of Belief.” Philosophical Studies 145: 395-405.

Steglich-Petersen, Asbjørn. 2011. "How to be a Teleologist about Epistemic Reasons.” In Reasons for Belief, edited by A. Reisner \& A. Steglich-Petersen. Cambridge: Cambridge University Press.

Steglich-Petersen, Asbjørn. 2013. “Truth as the Aim of Epistemic Justification.” In The Aim of Belief, edited by T. Chan. Oxford: Oxford University Press.

Steglich-Petersen, Asbjørn. 2014. "Knowing the Answer to a Loaded Question.” Theoria 80: 97125.

Steglich-Petersen, Asbjørn. 2018. "Epistemic Instrumentalism, Permission, and Reasons for Belief." In Normativity: Epistemic and Practical, edited by C. McHugh, J. Way \& D. Whiting. Oxford: Oxford University Press.

Steglich-Petersen, Asbjørn \& Mattias Skipper. 2019. “An Instrumentalist Account of How to Weigh Epistemic and Practical Reasons for Belief.” Mind 129: 1071-1094.

Steglich-Petersen, Asbjørn \& Mattias Skipper. 2020. "Instrumental Reasons for Belief: Elliptical Talk and Elusive Properties." In The Ethics of Belief and Beyond. Understanding Mental Normativity, edited by G. Ernst \& S. Schmidt. London: Routledge.

Thorstad, David. Forthcoming. "Inquiry and the Epistemic." Philosophical Studies.

Wallace, R. Jay. 2006. “Normativity, Commitment, and Instrumental Reason.” In Normativity and the Will: Selected Essays on Moral Psychology and Practical Reason. Oxford: Oxford University Press.

Way, Jonathan. 2010. "Defending the Wide-Scope Approach to Instrumental Reason.” Philosophical 
Studies 147: 213-233.

Way, Jonathan. 2012. “Transmission and the Wrong Kind of Reason.” Ethics 122: 489-515. 